\title{
Neurological disorder in a male llama originated by an abscedative myositis
}

\author{
Fumuso FG $^{1-3 *}$, Carretero $\mathrm{MI}^{1,2}$, Chaves $\mathrm{MG}^{1}$, Arraztoa $\mathrm{CC}^{1}$, Veiga $\mathrm{MF}^{1}$, Schapira $\mathrm{A}^{4}$ and Suranitti $\mathrm{A}^{5}$ \\ ${ }^{1}$ Instituto de Investigación y Tecnología en Reproducción Animal, Cátedra de Teriogenología. Universidad de Buenos Aires, Facultad de Ciencias Veterinarias, \\ Argentina \\ ${ }^{2}$ Clínica Médica de Pequeños Animales, Universidad de Buenos Aires, Facultad de Ciencias Veterinarias, Argentina \\ ${ }^{3}$ Consejo Nacional de Investigaciones Científicas y Técnicas (CONICET), Argentina \\ ${ }^{4}$ Cátedra de Patología Básica, Universidad de Buenos Aires, Facultad de Ciencias Veterinarias, Argentina \\ ${ }^{5}$ Servicio de Neurología del Hospital Escuela de Animales Pequeños, Universidad de Buenos Aires, Facultad de Ciencias Veterinarias, Argentina
}

\begin{abstract}
Background: Early diagnosis of neurological conditions in South American Camelids is crucial for treatments, prognosis and clinical patient development. Infectious agents, parasite, nutritional conditions or trauma, can cause neurological symptoms in camelids. Behavioral particularities can produce late infections and should be considered in differential diagnosis in clinical neurological cases.

Case description: A 4-year-old male llama was attended for consultation for a limp in his left hind leg. On clinical examination no general nor hind leg problems were found. After a week of the first consultation he presented an acute disorder to move. A complete neurological exam detected paraplegia with decreased deep sensation and hyporeflexia in the hind limbs were found. Complete blood work analysis and radiographs were performed, a moderate anemia and leucocytosis was detected and, radiographs suggested osteomyelitis on the spinal process in the third lumbar vertebra. Anti-inflammatory and antibiotic treatment with florfenicol was chosen and used at a dose of $20 \mathrm{mg} / \mathrm{kg}$ intramuscularly. The male llama died two weeks after the first sign appeared. At postmortem examination the most relevant lesion was a severe inflammatory infiltration delimited with connective tissue in the lumbar muscles, compatible with an abscedative myositis, Enterococcus spp. was isolated in the culture from the lesion.
\end{abstract}

Conclusion: To the authors knowledge this is the first report of a secondary and late infection produced as a consequence of aggressive behavior between males and should be consider as a differential diagnose in neurological disorders in these species.

\section{Introduction}

Neurological disorders in South American Camelids (SACs) have multiple origins, systemic infection and sepsis are reported to cause bacterial meningitis, as neurotrophic agents are not common [1]. The primary agents responsible for bacterial infection in camelids are Escherichia coli, Enterococcus spp., Pasteurella spp., Streptococcus spp. and Listeria spp. among others [2-4]. This pathology is usually difficult to diagnose due to the nonspecific signs that are associated with it and, the absence of neurological symptoms at early stages [1]. In this case report, an old injury in a male llama produced in a fight between males was the possible origin of a local pachymeningitis that cause neurological symptoms and later death. Clinical signs began with an intermittent limp in one of his hind legs, progressed to recumbency and a paraplegia with diminished sensibility on both hind limbs and absence of the anal reflex. In lambs, hind limb ataxia originated in a thoracolumbar abscess have been reported, but in this case the signs were cause by compression and posterior degeneration of the spinal cord [5]. There are no reports in llama of a neurological disorder as a late consequence of a fight between males, behavior that is common in these species and should be considered as a differential diagnosis.

\section{Case history}

A four-year-old male llama was attended for consultation for a limp in his left hind leg. A clinical evaluation was performed with the animal in a conscious state and under general anesthesia. The physical appearance of the male was normal on visual inspection with no abnormalities found on the leg. The male llama had his health plan for vaccines and deworming to date. No medical treatment was performed, and he was kept in observation until the next day, when he improved his condition and the limp disappeared. The male was kept in a pen for a week and was checked every day. After a week of the first consultation he presented an acute disorder to move. A complete neurological exam was performed under a conscious state of mind of the animal. The male llama presented a paraplegia with decreased deep sensation and hyporeflexia in the hind limbs. The anal reflex was diminished with maintenance of local sensitivity. There were no other neurological deficits within cranial nerves, sensory, motor or coordination in the forelimbs. An anti-inflammatory treatment was

${ }^{\star}$ Correspondence to: Fumuso FG, Instituto de Investigación y Tecnología en Reproducción Animal, Cátedra de Teriogenología, Clínica Médica de Pequeños Animales, Universidad de Buenos Aires, Facultad de Ciencias Veterinarias, Consejo Nacional de Investigaciones Científicas y Técnicas (CONICET), Argentina, E-mail: ffumuso@fvet.uba.ar

Key words: camelids, neurological disorders, abscedative myositis, behavior

Received: March 01, 2020; Accepted: March 24, 2020; Published: March 30 2020 
applied with the objective of reducing inflammation that cause the clinical signs, dexamethasone at a dose of $0.5 \mathrm{mg} / \mathrm{kg}$ intravenously was administered every $24 \mathrm{~h}$ for the first two days and the treatment was repeated three days after. Blood tests and radiographs were performed during the treatment period. These results are in Tables 1 and 2 and the images of the x-ray are in Figures 1 and 2. Samples of blood were obtained to analyze serology for Brucella spp., and negative results were found for B. canis, B. melitensis and B. abortus.

Hematological analysis showed a moderate anemia and leucocytosis. The biochemistry parameters showed elevated urea nitrogen level for the specie, without changes in creatinine serum and an increase in creatine kinase was also found.

The radiographs showed an image of a mixed lesion with lytic and proliferative areas of poorly defined contours that suggests osteomyelitis due to contiguity on the spinal process in the third lumbar vertebra. Also, a possible discoespondilitis could be present according to the image between the third and fourth lumbar vertebra.

Due to blood results, treatment consisted in supportive care, decreasing inflammation and attending the infection. Systemically anti-inflammatory as mention before were administered and florfenicol antibiotic was chosen and used at a dose of $20 \mathrm{mg} / \mathrm{kg}$ intramuscularly every $24 \mathrm{~h}$. The day after beginning antibiotic treatment the medical condition did not improve, the male was apathic with no connection with the environment and died that afternoon.

A complete necropsy was done, and samples of brain (cerebral cortex, brainstem, and cerebellum), heart, lung, liver, skin, trachea, esophagus, skeletal muscle, tongue, thyroid glands, kidneys, spleen, adrenal gland, small intestines, and colon were collected for histology. Tissues were immersion-fixed in $10 \%$ neutral buffered formalin $(\mathrm{pH}$ 7.2) for $24 \mathrm{~h}$, routinely embedded in paraffin, sectioned at $5 \mu \mathrm{m}$, and stained with hematoxylin and eosin for microscopic examination.

At postmortem examination the most relevant lesion was a severe inflammatory infiltration delimited with connective tissue

Table 1. Hematologic parameters found in the blood exam of the male llama

\begin{tabular}{|c|c|c|c|}
\hline & \multicolumn{2}{|c|}{ Case report } & Normal range \\
\hline Hematocrit (\%) & \multicolumn{2}{|c|}{$29^{\dagger}$} & $38.1 \pm 1.21$ \\
\hline Leukocytes $/ \mathbf{m m}^{3}$ & \multicolumn{2}{|c|}{$16900^{+}$} & $11.7 \pm 1.2$ \\
\hline Neutrophils & $93 \%$ & 15717 cells $/ \mathrm{mm}^{3}$ & $4,711-14,868$ \\
\hline Band neutrophils & -- & -- & $0-147$ \\
\hline Lymphocytes & $3 \%$ & 507 cells $/ \mathrm{mm}^{3}$ & $689-4,848$ \\
\hline Eosinophils & -- & -- & $647-4,867$ \\
\hline Monocytes & $1 \%$ & 169 cells $/ \mathrm{mm}^{3}$ & $0-1,009$ \\
\hline Basophils & -- & -- & $0-298$ \\
\hline
\end{tabular}

†Values that are abnormal for the date publish in the specie [11].

Table 2. Serum biochemistry parameters found in the blood exam of the male llama

\begin{tabular}{|c|c|c|}
\hline & Case report & Normal range \\
\hline Glucose (mg/dl) & $245^{\dagger}$ & $102-161$ \\
\hline Urea nitrogen (mg/dl) & $58^{\dagger}$ & $12-31$ \\
\hline Creatinine (mg/dl) & 1,71 & $1.2-2.9$ \\
\hline $\begin{array}{c}\text { Creatine kinase (CPK) } \\
\text { (UI/L) }\end{array}$ & $1712^{\dagger}$ & $0-137$ \\
\hline Albumin (g/dl) & 3,7 & $3.1-5.2$ \\
\hline Plasma protein (g/dl) & 4,5 & $4.8-7$ \\
\hline SGPT (UI/L & 2 & $0-14$ \\
\hline SGOT (UI/I) & 358 & $128-450$ \\
\hline FAS (UI/L) & 97 & $0-610$ \\
\hline
\end{tabular}

†Values that are abnormal for the date publish in the specie [10].

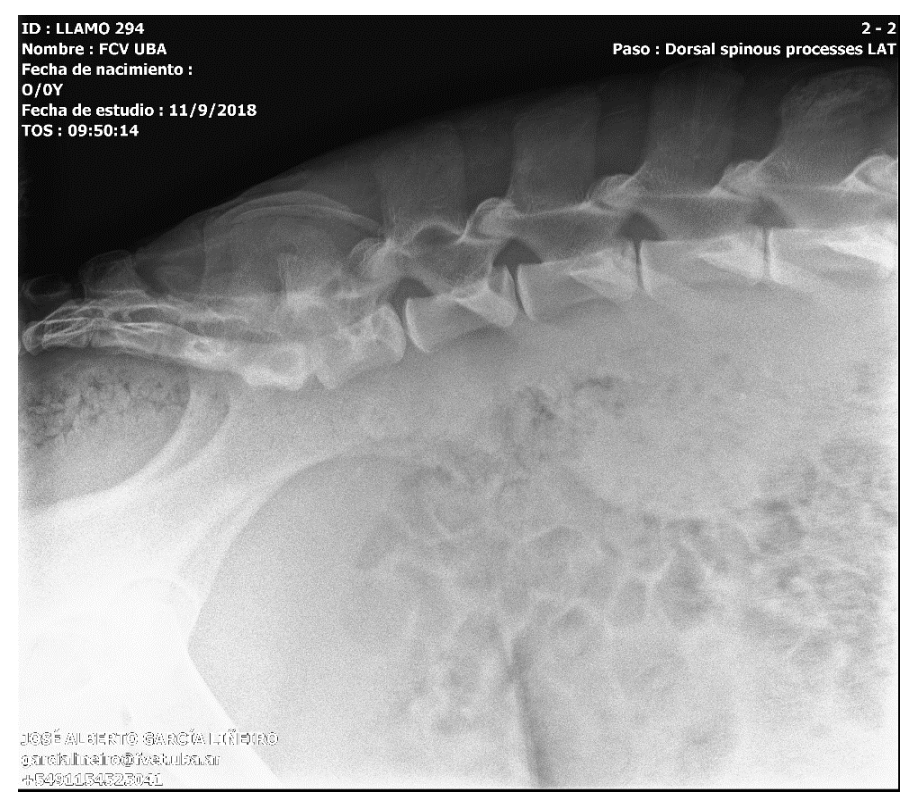

Figure 1. Latero-lateral Spine X-ray showing a possible osteomyelitis of the spina apophysis of the third lumbar vertebra and discoespondilitis between third and fourth lumbar vertebra

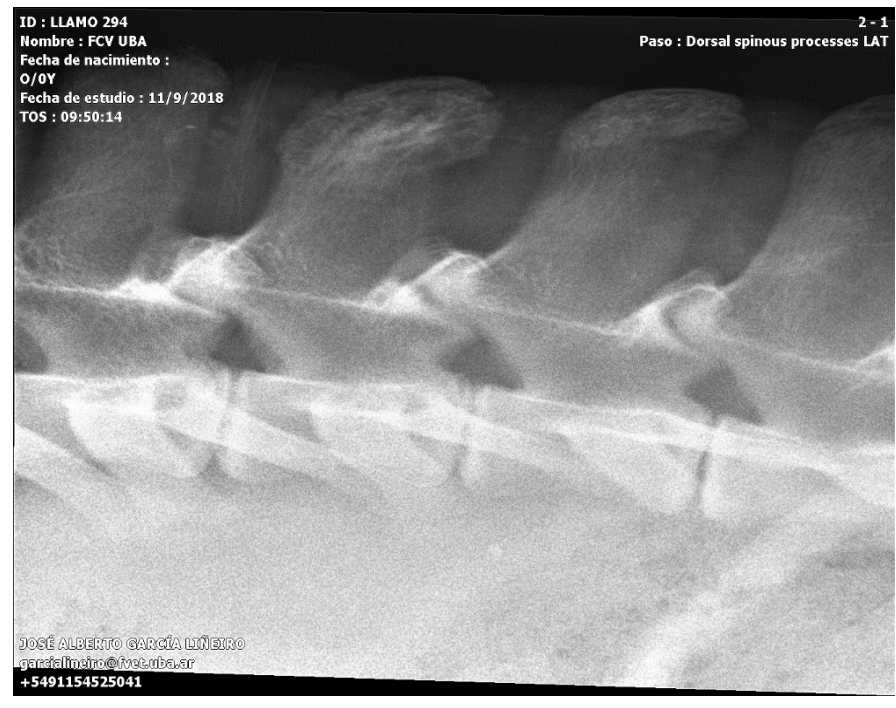

Figure 2. A close view of the latero-lateral spine X-ray showing osteomyelitis of the spinal apophysis of the third lumbar vertebra

in the lumbar muscles, compatible with an abscedative myositis (Figure 3). Spinal cord was also affected, and dura mater showed inflammatory infiltrated similar to the one found in the muscles. Histopathological analysis showed a severe inflammatory infiltrate in the lumbar muscles composed of a center of neutrophils and pyocytes, surrounded by plasma cells, lymphocytes and macrophages, delimited by granulation tissue characterized by numerous neoformed fibroblasts and blood vessels, with a smaller amount of collagen fibers. In these sectors, no viable muscle fibers were observed. The lumbar spinal cord presented several inflammatory cells in the dura mater and in minor measured in the arachnoid, similar to those described in the muscles. Also, during the necropsy samples for bacteriology were taken from both lesions, and Enterococcus spp. was isolated in the culture. 


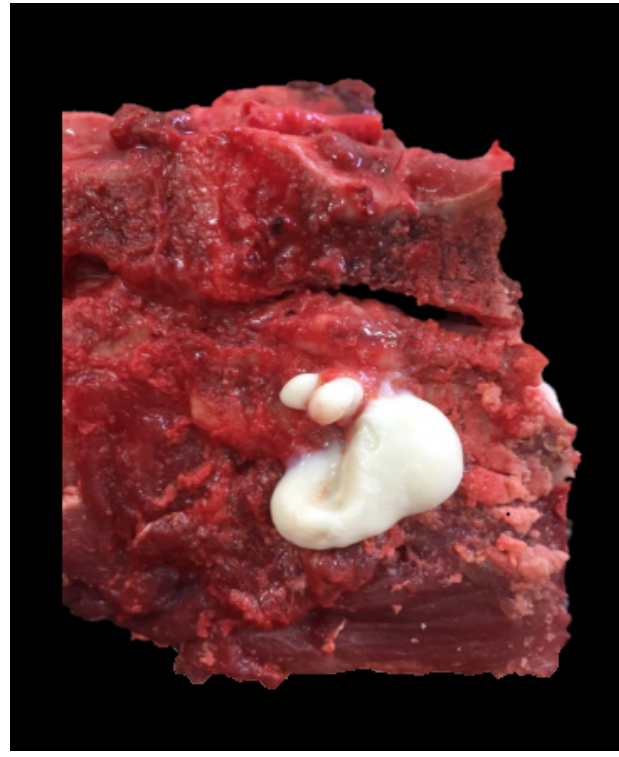

Figure 3. Abundant purulent exudate observed in the musculature adjacent to the lumbar vertebrae 3 and 4 . The secretion was well delimitated in part with connective tissue

\section{Discussion}

Neurological diseases in camelids can have different origins including the presence of infectious agents, such as West Nile virus and equine herpesvirus [6] or be produced due to bacterial meningitis [1]. Another source of neurological condition is polioencephalomalacia, pathology possibly caused by thiamine deficiency, like in ruminants [7]. Cervical traumas are frequent and more common than in other livestock species, having over $10 \%$ of frequency on camelids neurological clinical cases according to Whitehead et al. These authors reported parasitic myelopathy as the first cause of clinical neurological signs in south american camelids. This disease is produced by Parelaphostrongylus tenuis or commonly called meningeal worm. Toxic neuropathies, cranial trauma, hydrocephalus and tetany should be considered as differential diagnoses for neurological diseases in camelids [1].

Aggressive behavior between male camelids has been reported in guanacos [8] and is widely known by livestock farmers of these species. Majority of the fights include chase, spit, rush, body-slam and bites [8], also injuries in the perineal area, testicles and at the back are as well common [9]. In this case report, an old injury produced during a fight with another male 6 months before the clinical presentation, could be the possible origin of the abscedative myositis and neurological signs of the male llama. When the initial injured was produced, the male was attended, treated and trauma signs and lesions cured. The bacteria isolated from the lesion at necropsy was Enterococcus sp., one of the commonly reported in sudamerican camelids bacterial meningitis [1]. This agent produces nonspecific signs and absence of neurological symptoms at early stages complicating diagnosis and being unfavorable for the prognosis in this case. The anemia found in the blood work could be due to the chronic progress of the internal lesion. On the other hand, the increase in the urea nitrogen and CPK were possibly caused due to the prolonged recumbency of the patient.

This is the first report of a secondary and late infection produced as a consequence of aggressive behavior between males and should be consider as a differential diagnose in neurological disorders in these species $[10,11]$.

\section{Acknowledgements}

We would like to thank Dr. García Liñeiro M.V. from the Faculty of Veterinary Sciences of the University of Buenos Aires for taken the radiographs. Also, to thank the he radiology service of the school hospital of the Faculty of Veterinary Sciences of the University of Buenos Aires, Argentina.

\section{Authorship}

FFG, CMI, CMG, VMF, ACC: involved in patient management and treatment. ASc: pathologist involved in necropsy. ASu: involved in the neurological evaluation of the patient. FFG: writing. CMI, CMG, VMF, ACC, ASu, ASc: corrections.

\section{Conflict of interest}

None declared.

\section{References}

1. Cebra C, Gemensky-Metzler A (2014) Llama and alpaca care. Elsevier. First edition, 38: $427-464$.

2. Butt MT, Weldon A, Step D, De Lahunta A, Huxtable CR (1991) Encephalitis listeriosis in two adult llama (Lama glama): clinical presentations, lesions and immunofluorescence of Listeria monocytogenes in brainstem lesions. Cornell Vet 81: 251-258.

3. Burkhardt JE, Janovitz EB, Bowersock TL, Higgins R (1993) Septicemic Enterococcus infection in an adult llama. $J$ Vet Diagn Invest 5: 106-109.

4. Tsur I, Harmelin A, Dvir I, Yanai J (1996) Meningoencephalitis and brain abscessation due to Escherichia coli in a 2 week old alpaca cria. Aust Vet $J 74$ : 437-438. [Crossref]

5. Braun U, Suarez J, Gasparini S, Warislohner S, Dennler M (2016) Magnetic resonance imaging in a lamb with compression of the thoracic spinal cord by an abscess. Schweiz Arch Tierheilkd 158: 573-577. [Crossref]

6. Whitehead CE, Bedenice D (2009) Neurologic diseases in llamas and alpacas. Vet Clin North Am Food Anim Pract 25: 385-405. [Crossref]

7. Van Saun RJ (2006) Nutritional diseases in South American Camelids. Small Rum Res

8. Wilson P, Frankling L (1985) Male group dynamics and Inter-mal aggression of guanacoÂ's in Southern Chile. Z. Tiersphyschol 69: 305-328.

9. Pearson LK, Rodriguez JS, Tibary A (2014) Llama and alpaca Care. Elsevier. First edition, 19: 194-216.

10. Fowler ME (1989) Medicine and Surgery of South American Camelids. Hemic and lymphatic system, 15.: 263-272.

11. Reynafarje C, Faura J, Paredes A, Villavicencio D (1968) Erythrokinetics in highaltitude-adapted animals (llama, alpaca, and vicuña). J Appl Physiol 24: 93-97. [Crossref]

Copyright: (C2020 Fumuso FG. This is an open-access article distributed under the terms of the Creative Commons Attribution License, which permits unrestricted use, distribution, and reproduction in any medium, provided the original author and source are credited. 